\title{
Targeted temperature management: It is not yet time to change your target temperature
}

\author{
Reviewed by: David Clinkard, MSc*; Andrew Cameron, $\mathrm{BScH}^{*}$; Daniel Howes, $\mathrm{MD}^{* \dagger}$; Ian Ball ${ }^{\ddagger \S}$
}

Clinical question

In unconscious patients of out-of-hospital cardiac arrest, does targeted temperature management to $36^{\circ} \mathrm{C}\left(96.8^{\circ} \mathrm{F}\right)$ improve outcomes compared to the standard target of $32^{\circ} \mathrm{C}-34^{\circ} \mathrm{C}\left(89.6^{\circ} \mathrm{F}-93.2^{\circ} \mathrm{F}\right)$ ?

Article chosen

Nielson N, Wetterslev J, Cronberg T, et al. Targeted temperature management at $33^{\circ} \mathrm{C}$ versus $36^{\circ} \mathrm{C}$ after cardiac arrest. N Engl J Med 2013;369:2197-2206.

\section{Objective}

To determine which temperature, $33^{\circ} \mathrm{C}\left(91.4^{\circ} \mathrm{F}\right)$ or $36^{\circ} \mathrm{C}$ $\left(96.8^{\circ} \mathrm{F}\right)$, is associated with lower mortality and better neurologic function after cardiac arrest.

Keywords: Therapeutic Hypothermia, Cardiac Arrest, Target Temperature

\section{BACKGROUND}

Two randomized control trials (RCTs) suggested that targeted temperature management (TTM) (previously referred to as therapeutic hypothermia) to a target of $32^{\circ} \mathrm{C}-34^{\circ} \mathrm{C}\left(89.6^{\circ} \mathrm{F}-93.2^{\circ} \mathrm{F}\right)$ post-cardiac arrest is associated with improved mortality and neurologic function in ventricular fibrillation and ventricular tachycardia arrests. ${ }^{1,2}$ One trial failed to show the benefit from cooling patients presenting with pulseless electrical activity (PEA) and asystole. ${ }^{3}$ Both the 2009 and 2012 Cochrane Reviews concluded: "With conventional cooling methods... patients were 55\% more likely to leave the hospital without major brain damage."4
However, a meta-analysis by Nielson et al. ${ }^{5}$ (2012) described the overall quality of evidence as low and suggested that a large-scale clinical trial should be conducted. Nielson et al. ${ }^{5}$ hypothesized that the benefits demonstrated by TTM may come from the prevention of fever rather than from the induction of hypothermia. ${ }^{5}$ The reviewed study was designed to evaluate whether the degree of temperature reduction affects outcomes.

\section{POPULATION STUDIED}

The population included unconscious (Glasgow Coma Scale [GCS] less than 8) patients of 18 years and older who had suffered an out-of-hospital cardiac arrest of presumed cardiac origin.

\section{STUDY DESIGN}

This was a multicentre, randomized superiority trial. Treating physicians were not blinded to the degree of cooling; however, all patient outcomes were assessed by blinded personnel. The study took place between November 2010 and July 2013 across 36 intensive care units in Australia and Europe. Patients were block randomized in a 1:1 ratio and stratified by the site. Exclusion criteria included time from return of spontaneous circulation (ROSC) to screening greater than 240 minutes, unwitnessed arrest with asystole as the initial rhythm, suspected or known intracranial event, and a body temperature under $30^{\circ} \mathrm{C}\left(86^{\circ} \mathrm{F}\right)$.

From the *Department of Emergency Medicine, Queen's University, Kingston, ON; TCritical Care Medicine Program, Queen's University, Kingston, ON; ‡Division of Critical Care Medicine, Department of Medicine, Western University, London, ON; and §Department of Molecular Toxicology, Western University, London, ON

Correspondence to: David Clinkard, Undergraduate Medical Education, Queen's University, 80 Barrie Street, Kingston, ON K7L 3N6; dclinkard@qmed.ca.

This article has been peer reviewed. 
Sedation was required for 36 hours, but both sedation and cooling protocols were left to the discretion of the treating physicians. The core temperature was measured with urinary bladder, esophageal, or intravascular probes. Patients were rewarmed to $37^{\circ} \mathrm{C}\left(98.6^{\circ} \mathrm{F}\right)$ after 28 hours at a rate of $0.5^{\circ} \mathrm{C}\left(32.9^{\circ} \mathrm{F}\right)$ per hour and maintained between $37^{\circ} \mathrm{C}\left(98.6^{\circ} \mathrm{F}\right)$ and $37.5^{\circ} \mathrm{C}\left(99.5^{\circ} \mathrm{F}\right)$ until 72 hours post-cardiac arrest. The withdrawal of life-support recommendations were made using a standardized protocol.

\section{OUTCOMES}

The primary outcome was survival at trial completion. The secondary outcomes were a composite measure of neurologic performance using the Cerebral Performance Category scores and modified Rankin Scale (at 180 days, and death at 180 days).

\section{RESULTS}

Four hundred seventy-three patients were randomized to the $33^{\circ} \mathrm{C}\left(91.4^{\circ} \mathrm{F}\right)$ group and 466 were randomized to the $36^{\circ} \mathrm{C}\left(96.8^{\circ} \mathrm{F}\right)$ group. Baseline characteristics in the two groups were similar. Eighty percent of the patients presented with a shockable rhythm, $12 \%$ in asystole, and $8 \%$ in PEA.

Mean temperatures at presentation were $35.2^{\circ} \mathrm{C}$ $\left(95.36^{\circ} \mathrm{F}\right)$ and $35.3^{\circ} \mathrm{C}\left(95.54^{\circ} \mathrm{F}\right)$ for the $33^{\circ} \mathrm{C}\left(91.4^{\circ} \mathrm{F}\right)$ and $36^{\circ} \mathrm{C}\left(96.8^{\circ} \mathrm{F}\right)$ groups, respectively. Patients reached their target temperatures, $36^{\circ} \mathrm{C}\left(96.8^{\circ} \mathrm{F}\right)$ at 5 hours and $33^{\circ} \mathrm{C}\left(91.4^{\circ} \mathrm{F}\right)$ at 8 hours, after randomization. The time from return of circulation to the target temperature was not reported.

There was no mortality difference between the two groups, $235 / 473(50 \%)$ in the $33^{\circ} \mathrm{C}\left(91.4^{\circ} \mathrm{F}\right)$ group versus $225 / 466(48 \%)$ in the $36^{\circ} \mathrm{C}\left(96.8^{\circ} \mathrm{F}\right)$ group (hazard ratio 1.06; 95\% confidence interval of 0.89-1.28; $p=0.51)$. There was no difference in neurologic outcome using the modified Rankin Scale, Cerebral Performance Category scores, or 180-day mortality. An analysis by per-protocol (those who fulfilled all protocol steps), a modified intention-to-treat (except those patients withdrawing consent or not fulfilling inclusion criteria and never receiving the intervention), and an analysis of predefined subgroups failed to demonstrate any difference in primary outcome.

The authors in this study concluded that in unconscious patients of out-of-hospital cardiac arrest of presumed cardiac cause, hypothermia at a targeted temperature of $33^{\circ} \mathrm{C}\left(91.4^{\circ} \mathrm{F}\right)$ does not confer a benefit compared to a targeted temperature of $36^{\circ} \mathrm{C}\left(96.8^{\circ} \mathrm{F}\right)$.

\section{COMMENTARY}

This study addresses a contentious issue in postresuscitative care of whether the benefits of current protocols are due to hypothermia or simply fever prevention. The trial included more TTM patients than all previous studies combined due to an impressive international collaboration.

This superiority trial was powered to detect an $11 \%$ absolute mortality difference between the $36^{\circ} \mathrm{C}\left(96.8^{\circ} \mathrm{F}\right)$ group and the $33^{\circ} \mathrm{C}\left(91.4^{\circ} \mathrm{F}\right)$ group (a relative risk reduction of $20 \%$ ). A negative superiority trial should not be interpreted as proof that no difference exists between interventions. For example, there may have been an absolute risk reduction of $5 \%$, but this would not have been detected with the given sample size. An equivalence or noninferiority trial design is necessary to correctly conclude that $33^{\circ} \mathrm{C}\left(91.4^{\circ} \mathrm{F}\right)$ is not better than $36^{\circ} \mathrm{C}\left(96.8^{\circ} \mathrm{F}\right){ }^{6}$ Failure to demonstrate superiority is not the same as proving equivalence; therefore, the proper interpretation of this failed superiority trial would be that there was no benefit from raising the target temperature from $33^{\circ} \mathrm{C}\left(91.4^{\circ} \mathrm{F}\right)$ to $36^{\circ} \mathrm{C}$ $\left(96.8^{\circ} \mathrm{F}\right)$. This finding may be the result of a number of design features that make the $33^{\circ} \mathrm{C}\left(91.4^{\circ} \mathrm{F}\right)$ and $36^{\circ} \mathrm{C}$ $\left(96.8^{\circ} \mathrm{F}\right)$ groups appear similar, potentially minimizing the effect of temperature on the primary outcome.

\section{PATIENT POPULATION}

The authors excluded patients with unwitnessed asystolic arrests. However, the authors included unwitnessed cardiac arrests (i.e., $11 \%$ in the $33^{\circ} \mathrm{C}\left[91.4^{\circ} \mathrm{F}\right]$ ) group and $10 \%$ in the $36^{\circ} \mathrm{C}\left[96.8^{\circ} \mathrm{F}\right]$ group), as well as patients (approximately 20\%) presenting in asystole and PEA. In the original trials, the fraction (i.e., $1 \%$ in the Hypothermia After Cardiac Arrest [HACA] study and $5 \%$ in the Bernard study) of unwitnessed arrests were lower, and PEA and asystolic arrests were excluded. Unwitnessed cardiac arrests and those that present with PEA and asystoles have very poor outcomes and, therefore, less chance of benefiting from TTM. The inclusion of these populations reduces the likelihood that a mortality benefit will be demonstrated. ${ }^{4}$ 


\section{TREATMENT}

Most aspects of patient care, including the cooling and sedation protocols, were left to the discretion of the unblinded treating physicians and were not reported. This improves generalizability, but may introduce bias, because it leads to more variation within the treatment groups. Increased intragroup variation may potentially make it less likely that a statistical difference will be demonstrated between groups.

The study protocol permitted a delay to the initiation of therapy, despite recommending that the target temperature be achieved as quickly as possible. For the subgroup of patients with cooling times reported, it took 8 hours for the $33^{\circ} \mathrm{C}\left(91.4^{\circ} \mathrm{F}\right)$ group to achieve the target. Standard reporting for TTM research is to report the time to a target temperature from ROSC or, in some cases, from the initiation of cooling. This trial reported time from randomization, a process that was allocated up to 4 hours. With a mean time of 120 minutes to randomization and a mean cooling time of 8 hours, some patients may not have achieved the target temperature for over 10 hours. ${ }^{7}$ In comparison, HACA reported a median time to target temperature of 8 hours from ROSC, a 20\% difference. ${ }^{2}$ Although the optimal time of cooling initiation post ROSC is not known, the delay in achieving a target temperature could reduce the likelihood of finding a difference between the groups.

There are a number of other commendable attributes of this study that warrant mention. The neurologic prognostication of patients was significantly improved over previous trials. A blinded treating physician performed a neurologic evaluation 72 hours after the end of the intervention and issued a recommendation for the continuation or withdrawal of therapy. The trial protocol specified criteria for the withdrawal of life-sustaining therapy, although the ultimate decisions remained at the discretion of the unblinded treating team.

Blinding of treatment groups is unrealistic in this type of study, but the authors did ensure that prognosticators, follow-up assessors, statisticians, and authors were blinded to the treatment group assignment. During the analysis phase, the groups were identified only as 0 and 1 , and the manuscript was written and approved before the code was broken.

\section{CONCLUSIONS}

Despite the impressive trial size and other aforementioned strengths, clinicians should be cautious about changing their practices from the current American Heart Association guidelines of cooling to $32^{\circ} \mathrm{C}-34^{\circ} \mathrm{C}$ $\left(89.6^{\circ} \mathrm{F}-93.2^{\circ} \mathrm{F}\right) .^{8}$ There are now two positive and two negative trials on the survival benefit of TTM post-cardiac arrest, each with methodologic differences. ${ }^{1,2,4,9}$ Both negative trials included PEA and asystolic arrests, whereas both positive trials excluded them. This study does suggest important clinical concepts that deserve further investigation, in particular, the optimal temperature of therapeutic hypothermia and the acceptable delay in achieving the target temperature.

Based on previous RCTs showing survival benefit, a strong safety profile, and the failure of this study to show superiority, a change in the current target temperature aiming at $33^{\circ} \mathrm{C}\left(91.4^{\circ} \mathrm{F}\right)$ may not be warranted.

Competing interests: None declared.

\section{REFERENCES}

1. Bernard SA, Gray TW, Buist MD, et al. Treatment of comatose survivors of out-of-hospital cardiac arrest with induced hypothermia. N Engl 7 Med 2002;346(8):557-63.

2. Hypothermia after Cardiac Arrest Study Group. Mild therapeutic hypothermia to improve the neurologic outcome after cardiac arrest. N Engl 7 Med 2002;346(8):549-56.

3. Hachimi-Idrissi S, Corne L, Ebinger G, et al. Mild hypothermia induced by a helmet device: a clinical feasibility study. Resuscitation 2001;51(3):275-81.

4. Arrich J, Holzer M, Havel C, et al. Hypothermia for neuroprotection in adults after cardiopulmonary resuscitation. Cochrane Database Syst Rev 2012;9:CD004128.

5. Nielsen N, Wetterslev J, Al-Subaie N, et al. Target temperature management after out-of-hospital cardiac arresta randomized, parallel-group, assessor-blinded clinical trial-rationale and design. Am Heart 7 2012;163(4):541-8.

6. Lesaffre E. Superiority, equivalence, and non-inferiority trials. Bull NYU Hosp ft Dis 2008;66(2):150-4.

7. Nielsen N. Canadian guidelines of the use of targeted temperature management (TTM) [Email]. Message to: Daniel Howes. January 8, 2014.

8. Field JM, Hazinski MF, Sayre MR, et al. Part 1: executive summary: 2010 American Heart Association Guidelines for Cardiopulmonary Resuscitation and Emergency Cardiovascular Care. Circulation 2010;122(18 Suppl 3):S640-56.

9. Nielsen N, Wetterslev J, Cronberg T, et al. Targeted temperature management at $33^{\circ} \mathrm{C}$ versus $36^{\circ} \mathrm{C}$ after cardiac arrest. N Engl 7 Med 2013;369(23):2197-206. 